\title{
Aa. Vv., Le théâtre au XVIIe siècle: pratiques du mineur
}

\section{Monica Pavesio}

\section{(2) OpenEdition}

\section{Journals}

\section{Edizione digitale}

URL: http://journals.openedition.org/studifrancesi/30156

DOI: 10.4000/studifrancesi.30156

ISSN: 2427-5856

\section{Editore}

Rosenberg \& Sellier

\section{Edizione cartacea}

Data di pubblicazione: 1 avril 2006

Paginazione: 145-146

ISSN: 0039-2944

\section{Notizia bibliografica digitale}

Monica Pavesio, «Aa. Vv., Le théâtre au XVIle siècle: pratiques du mineur», Studi Francesi [Online], 148

(XLX | I) | 2006, online dal 30 novembre 2015, consultato il 22 avril 2021. URL: http://

journals.openedition.org/studifrancesi/30156 ; DOI: https://doi.org/10.4000/studifrancesi.30156

Questo documento è stato generato automaticamente il 22 avril 2021.

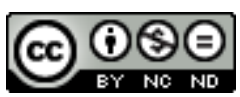

Studi Francesi è distribuita con Licenza Creative Commons Attribuzione - Non commerciale - Non opere derivate 4.0 Internazionale. 


\title{
Aa. Vv., Le théâtre au XVIIe siècle: pratiques du mineur
}

\author{
Monica Pavesio
}

\section{NOTIZIA}

Le théâtre au XVIIe siècle: pratiques du mineur, «Littératures classiques», 51, été 2004.

1 Il volume 51 di Littératures classiques, curato da Hélène Baby con la partecipazione di Christian Delmas, è dedicato allo studio dei "Minores" nel teatro francese del XVII secolo.

2 Come ricorda la curatrice nella presentazione, l'aggettivo "minore" puo essere inteso sia a livello quantitativo che qualitativo. Si definisce "minore" un elemento non dominante all'interno di un gruppo: è il caso, per esempio, dei Plaideurs di Racine, sola commedia del corpus drammatico interamente tragico del drammaturgo; risulta "minore" anche ciò che è d'importanza secondaria, ossia un'opera o un autore di second'ordine nel campo artistico e letterario.

Questa seconda accezione del termine, sconosciuta nel XVII secolo, è piuttosto recente. Solo alla fine del XIX secolo, si inizia a parlare di autori di second'ordine e di opere poco conosciute, ma non viene ancora definita una distinzione precisa fra "maggiori" e "minori". In seguito, a livello teatrale, in un secolo come il XVII, con un trio drammaturgico di primaria importanza composto da Corneille, Racine e Molière, si è arrivati ad una facile gerarchizzazione che considera tutti gli altri drammaturghi necessariamente e naturalmente "minori".

4 Oggi l'aggettivo sostantivato "minore" viene utilizzato dai curatori del volume per indicare, non solo le opere ed i drammaturghi reputati di second'ordine, ma tutte le componenti minori della creazione drammatica francese del XVII secolo.

5 Il volume è suddiviso in tre sezioni. La prima "Ecritures mineures" esamina le pratiche testuali o extratestuali considerate "minori", come la puntuazione (A. RIFFAUD, Éditions critiques et description matérielle: un enjeu mineur? L'exemple de la ponctuation dans le théâtre 
imprimé, pp. 17-42), la disascalia (V. LOCHERT, La didascalie dans le théâtre français au XVII siècle: une pratique mineure?, pp. 43-67): le sentenze (E. GAROFALO, Forme majeure et forme mineure de l'écriture tragique: le raisonnement sentencieux chez Corneille e Racine, pp. 91-103).

6 La seconda «Mineurs ou majeurs» illustra il passaggio dal «minore» al «maggiore», in funzione del successo e della legittimazione teatrale di una pièce. Alcuni studi si soffermano sui generi minori di grande successo come la farsa, (Ch. Mazouer, La farce au XVII siècle. Un genre populaire, pp. 157-70), la commedia «à l'espagnole» dei contemporanei di Molière (V. STEMBERG, La comédie des contemporains de Molière: une production mineure?, pp. 171-85); altri sulla legittimazione dottrinale dei generi minori (Ch. DELMAS, Légitimation doctrinale et genre mineur. Le cas du théâtre à machines, pp. 225-31. M. HAWCROFT, Le discours de la majoration et de la minoration chez l'abbé d'Aubignac: création et fissuration de hiérarchies dans la Pratique du théâtre, pp. 253-67).

7 L'ultima sezione «Frontières des genres majeurs» illustra i generi minori della tragicommedia (H. BABY, De la légitimation paradoxale: la tragi-comédie au temps de Richelieu, pp. 287-303), della commedia eroica (G. REVAZ, La comédie héroïque et la tragédie: quelle distinction générique?, pp. 305-315) e della comédie ballet (M. Cl. CANOVA-GREEN, Marginale ou marginalisée? La comédie-ballet moliéresque, pp. 317-334), per evidenziare come dottrina e successo siano spesso due elementi contradditori e come i generi considerati minori ottengano una "maggiorazione" dovuta al successo delle loro messe in scena.

Tutti i lavori presenti nel volume partono dai "minori", per arrivare a parlare dei "maggiori". Lo scopo finale di questo interessante numero di Littératures classiques è infatti quello di misurare l'apporto delle pratiche minori nella comprensione delle grandi correnti drammatiche che attraversano il XVII secolo. 